\title{
THORACIC SPINE CANAL STENOSIS WITH CAUDA EQUINE SYNDROME: CASE REPORT
}

\author{
Primadenny Ariesa Airlangga ${ }^{1}$, Arifin ${ }^{2 *}$ \\ ${ }^{1}$ Staff of Orthopaedic and Traumatology Department, Faculty of Medicine, Universitas \\ Airlangga/Dr Soetomo General Hospital, Surabaya \\ ${ }^{2}$ Resident of Orthopaedic and Traumatology Department, Faculty of Medicine, Universitas \\ Airlangga/Dr Soetomo General Hospital, Surabaya \\ *Corresponding Author: Arifin, Resident of Orthopaedic and Traumatology Department, \\ Faculty of Medicine, Universitas Airlangga/Dr Soetomo General Hospital, Jl. Mayjen Prof. Dr. \\ Moestopo 6-8, Surabaya. \\ E-mail: arifin85dr@gmail.com
}

\begin{abstract}
ABSTRAK
Latar Belakang: Kasus kanal stenosis thorakal dengan sindroma cauda equine jarang ditemukan. Canal thoracal relatif lebih sempit dibandingkan dengan servikal dan lumbal, sehingga sedikit penekanan pada daerah thorakal bawah setinggi vertebra thorakal 11 yang merupakan awal keluarnya akar saraf cauda equine dapat menimbulkan keluhan sindroma cauda equine.
\end{abstract}

Kasus: Seorang laki-laki 50 tahun dengan nyeri kedua kaki sejak 3 tahun, disertai kelemahan tungkai, kebas pada pantat, dan disfungsi ereksi. Pemeriksaan MRI thorakal menunjukkan spinal stenosis berat setinggi vertebra thorakal 11-12 disertai hipertrofi ligamentum flavum. Berikutnya laki-laki 70 tahun mengeluh kedua kaki lemah sejak 1 minggu, disertai nyeri di pinggang, kebas di pantat, dan sulit buang air besar. Pemeriksaan MRI thorakal tampak spinal stenosis berat pada vertebra thoracal 10-11. Kedua pasien segera dilakukan operasi selective decompression, laminotomy, dan flavectomy pada level thorakal menunjukkan hasil yang memuaskan berdasarkan perbaikan gejala klinis.

Diskusi: Kelemahan tungkai, hipoestesi pada daerah pantat dan kemaluan, disfungsi ereksi merupakan sindroma cauda equine. Keluarnya saraf cauda equine pertama dapat melalui level thorakal 11, sehingga adanya stenosis pada level tersebut ke bawah dapat menimbulkan gejala sindroma cauda equine. Pemeriksaan MRI diperlukan untuk meyakinkan bahwa adanya spinal stenosis berat pada level vertebra thorakal lumbal, sesuai level gangguan neurologis. Tindakan dekompresi segera dilakukan pada kasus sindroma cauda equine karena merupakan kegawatan. Kesimpulan: Pada kasus dengan keluhan sindroma cauda equine, kanal stenosis thorakal bisa merupakan penyebabnya akibat penekanan daerah thorakal bawah yang merupakan awal keluarnya akar saraf cauda equine. Konfirmasi diagnosis akurat dengan MRI.

Kata kunci: Kanal stenosis thorakal, sindroma cauda equine, MRI thorakal

\begin{abstract}
Background: Cases of thoracic stenosis with cauda equina syndrome are rare. The thoracal canal is relatively narrow compared with cervical and lumbar, so the less pressure on the lower thoracal region is the thoracic vertebral height 11 which is the initial release of the cauda equine nerve root can cause complaints of cauda equina syndrome.

Case: A 50-year-old male presented pain in both legs for 3 years, accompanied by weakness in the legs, numbness in the buttocks, and erectile dysfunction. Thoracal MRI examination shows severe spinal stenosis at $11^{\text {th }}-12^{\text {th }}$ thoracal vertebra with ligamentum flavum hypertrophy. Second patient, a 70-year-old man complained of weak legs since 1 week, accompanied by low back pain, numbness in the buttocks, and difficulty defecating. Thoracal MRI examination
\end{abstract}


shows severe spinal stenosis in the $10^{\text {th }}-11^{\text {th }}$ thoracal vertebra. Both patients immediately underwent selective decompression surgery, laminotomy, and flavectomy at thoracal level showed satisfactory results based on improvement in clinical symptoms.

Discussion: Leg weakness, hypoesthesia in the buttocks and pubic area, erectile dysfunction is the cauda equina syndrome. The exit of the first cauda equine nerve can be placed at $11^{\text {th }}$ thoracic vertebra, so the presence of stenosis at that level and bellow can cause symptoms of the cauda equina syndrome. MRI examination is needed to ensure that there is severe spinal stenosis at the level of the thoracal-lumbar spine, according to the level of neurological disorders. The surgery of decompression is immediately carried out in the case of cauda equina syndrome because it is an emergency state.

Conclusion. In cases with complaints of the cauda equina syndrome, thoracic stenosis can be the cause due to stenosis of the lower thoracic region which is the initial root of the cauda equina nerve. Confirm accurate diagnosis is with MRI.

Keywords: thoracic spinal canal stenosis, cauda equine syndrome, thoracal MRI

\section{PENDAHULUAN}

Stenosis pada canalis spinal thoracal merupakan kasus yang jarang. Manifestasi klinis meliputi gejala dan tanda focal radiculopathy dan atau myelopathy yang sering ditemukan yaitu pada regio cervical dan lumbal. ${ }^{1,2}$ Kasus spinal stenosis yang mengenai level thoracal jarang ditemukan dan gejala yang nampak dapat bervariasi. Tidak jarang canal stenosis setinggi thorakal juga disertai dengan gejala cauda equine syndrome. Oleh karena canal thoracal relatif lebih sempit dibandingkan dengan servikal dan lumbal, sehingga penekanan pada canal thoracal menyebabkan nyeri radicular yang ditimbulkan sulit ditentukan lokasinya. ${ }^{3}$

Seringkali pasien dengan keluhan kelemahan ekstremitas bawah selalu dikaitkan dengan adanya patologi pada level lumbal. Sehingga penegakkan diagnosis pun sering tertuju pada level tersebut meskipun adanya patologi pada lumbal yang dapat terjadi bersama dengan patologi setinggi thorakal. Gejala myelopathy thoracal level bawah setinggi T10-12 (epiconus) menunjukkan gejala nyeri dan kelemahan extremitas bawah yang menyerupai gangguan radiculopathy lumbal. ${ }^{4}$

Kasus spinal stenosis pada berbagai level vertebra menimbulkan variasi gejala dan tanda. Adanya gejala cauda equine syndrome pada canal stenosis thoracal jarang ditemukan. Munculnya cauda equine syndrome tergantung pada level stenosis yang terjadi pada vertebra thorakal dan lumbal. Tidak semua stenosis pada vertebra akan menimbulkan gejala cauda equine syndrome. Cauda equine syndrome ini merupakan kasus kegawatan yang harus segera ditangani dan dilakukan tindakan. ${ }^{4}$

\section{LAPORAN KASUS}

Pasien pertama, seorang laki-laki umur 50 tahun, datang di poliklinik orthopaedi dengan keluhan utama nyeri pada 
kedua betis. Nyeri pada kedua betis seperti dicengkeram sejak 3 tahun yang lalu. Nyeri dirasakan memberat dalam 2 bulan berikutnya, disertai lemah pada kedua tungkai sehingga berjalan harus dengan bantuan tongkat. Nyeri dirasakan memberat bila pasien berjalan sejauh kurang lebih 100 meter. Nyeri berkurang dengan istirahat. Nyeri dirasakan makin memberat 1 tahun terakhir, sehingga pasien kesulitan berjalan dan harus dibantu walker. Pasien merasakan kesemutan pada kedua kaki dan daerah perineum. Gangguan ereksi muncul mulai 1 tahun terakhir. Pasien tidak memiliki penyakit diabetes mellitus. Kekuatan motorik dan tonus ektremitas bawah menurun dengan sensorik terdapat saddle anesthesia dan hipoestesi mulai setinggi thorakal 11. Pemeriksaan laboratorium dalam rentang normal. Dari MRI didapatkan multiple canal stenosis setinggi korpus vertebra thorakal 11-12 sampai dengan setinggi korpus vertebra lumbal 4-5 yang ditunjukkan pada Gambar 1 dan 2.

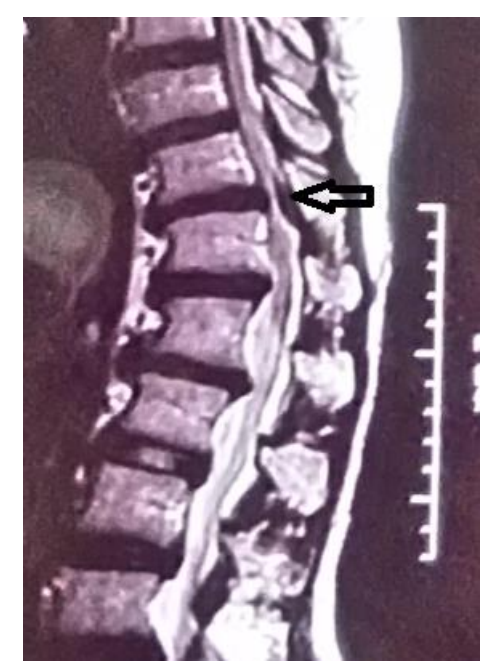

Gambar 1. Irisan MRI sagital didapatkan canal stenosis setinggi vertebra thoracal 1112 dan penebalan ligamentum flavum

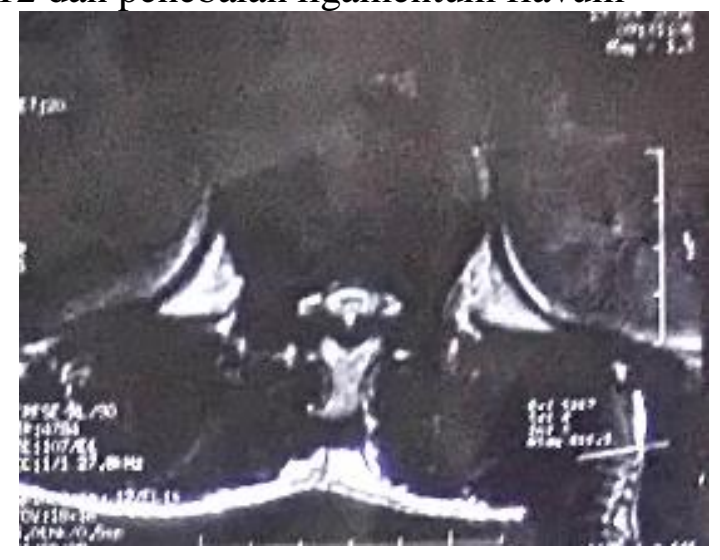

Gambar 2. Irisan MRI axial

Pasien didiagnosis sebagai canal stenosis thoracalis setinggi vertebra thoracalis 11 dengan cauda equine syndrome. Setelah pasien rawat inap, dilakukan tindakan operasi dekompresi, laminotomy dan flavectomy setinggi vertebra thorakal 11-12. Pasien keluar rumah sakit setelah 3 hari perawatan pascaoperasi. Dari evaluasi didapatkan perbaikan klinis penurunan nyeri mencengkeram, namun saddle anestesi mesih menetap. Kekuatan motorik belum kembali membaik sampai 6 bulan pascaoperasi.

Pasien kedua, laki-laki umur 74 tahun datang ke poliklinik orthopaedi dengan keluhan utama kedua kaki tidak bisa digerakkan sejak 2 minggu sebelum masuk rumah sakit. Awalnya kedua kaki terasa mulai lemah, memberat dalam 1 bulan terakhir. Pasien juga mengeluhkan nyeri daerah punggung dan pinggang yang menjalar ke kedua kaki. Bokong terasa kebas 
dan sekitar daerah kemaluan. Pasien hanya mampu berjalan dalam jarak 100 meter. Pasien mengalami gangguan buang air besar dan buang air kecil sejak 10 hari. Saat ini pasien tidak dapat menggerakkan kaki dan berjalan. Tidak didapatkan riwayat penyakit diabetes mellitus. Pada pemeriksaan fisik didapatkan adanya hipoestesi mulai setinggi dibawah umbilikus. Rasa tebal pada daerah bokong dan sekitar kemaluan. Dengan kekuatan motorik yang menurun tidak mampu melawan gravitasi. Tonus otot kaki menurun dengan reflek patologis tidak ada. Pada pemeriksaan laboratorium dalam rentang normal. Hasil MRI seperti tamapak pada gambar 3 dan 4 menunjukkan adanya Left paracentral extruded disc Th 10-11, menekan spinal cord dan mild foraminal stenosis L1-2 dan L 2-3.

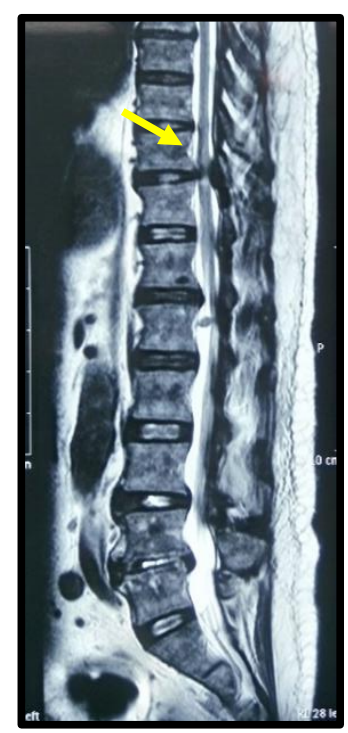

Gambar 3. MRI irisan sagittal

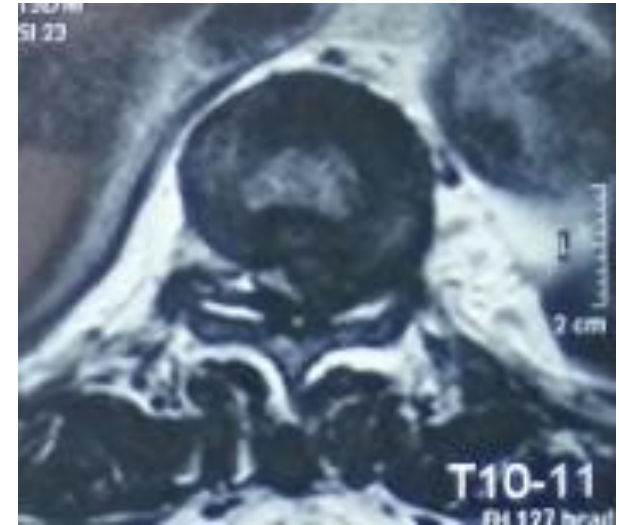

Gambar 4. MRI irisan axial

Pasien didiagnosis dengan Canal Stenosis setinggi Vertebra Th 10 dengan Cauda Equina Sydrome. Setelah pasien rawat inap dilakukan tindakan dekompresi, laminotomy, dan flavectomy setinggi vertebra thoracal 10-11. Perbaikan klinis dirasakan pasien setelah 1 bulan pascaoperasi. Pasien membaik motorik tungkai bawah dan keluhan rasa tebal berangsur berkurang. Pasien mampu berjalan dengan bantuan walker.

\section{DISKUSI}

Thoracic spinal stenosis didefinisikan sebagai penurunan kapasitas canalis spinalis thoracal diikuti dengan penekanan corda spinalis dan atau akar saraf yang menimbulkan berbagai gejala klinis, penurunan kapasitas dikarenakan oleh atau lebih faktor patologis meliputi osifikasi ligamen pada canal spinal, herniasi diskus, osteofit vertebra posterior dan developmental spinal stenosis. Penyempitan canal spinalis dapat terjadi pada central 
canal, lateral recess atau foramen. Masingmasing menimbulkan gejala yang berbeda. Pasien dengan central canal stenosis menunjukkan gejala claudication neurogenic, sedangkan pada penderita dengan lateral recess atau foramen stenosis menimbulkan gejala radicular pain. ${ }^{1,2}$

Penekanan pada spinal cord thoracal akan menimbulkan lesi Upper Motor Neuron (UMN) pada ekstremitas bawah, bersama dengan gangguan sensorik tergantung dari besarnya keterlibatan dari kolumna dorsalis atau traktus spinotalamikus. Lesi UMN ini akibat dari lesi pada traktus kortikospinalis descending pada cornu anterior yang menginervasi ekstremitas bawah. ${ }^{5}$ Gambar 5 menjelaskan anatomi canal vertebra dengan spinal cord yang relatif lebih pendek. Akar saraf cauda equine dapat dimulai setinggi level vertebra thorakal bawah $11 .^{6}$

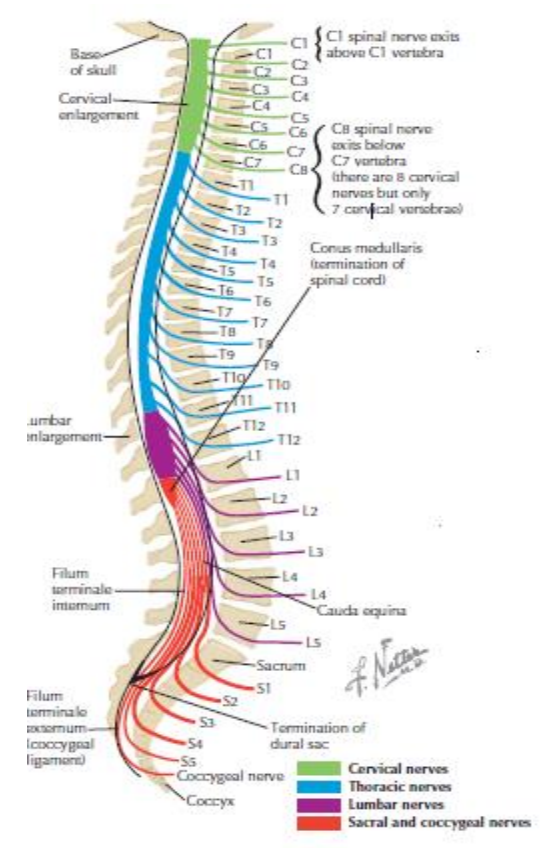

Gambar 5. Hubungan segmen spinal cord dan akar saraf dengan kolumna vertebra ${ }^{6}$

Secara neurofisiologi, lesi yang melibatkan cauda equina merupakan lesi Lower Motor Neuron (LMN). Oleh karena itu, pasien dengan cauda equina syndrome bisa menimbulkan derajat yang bervariasi kelemahan otot dan gangguan sensorik juga penurunan refleks. ${ }^{7}$ Gangguan Neurogenic bladder merupakan bagian yang penting dari Cauda Equine Syndrome (CES). CES menyebabkan lesi LMN yang memutus jalur refleks. Akibatnya, pasien kehilangan sensorik dan inervasi motorik pada kandung kemih. Pasien tidak dapat merasakan kandung kemih yang mengalami distensi. Selanjutnya, pasien tidak bisa kontraksi dari detrusor uri dan relaksasi sphincter uri, sehingga terjadi retensi / incontinensia. ${ }^{8}$ 
Cedera iskemik merupakan faktor penting dalam patofisiologi CES. Vaskularisasi utama dari spinal cord adalah arteri spinalis anterior dan arteri dorsalateral. Arteri yang memvaskularisasi akar saraf kurang dijelaskan. $U$ shape merupakan area hipovaskuler di bawah level conus medularis berkorelasi dengan anastomosis vaskuler pada cauda equine. Area hipovaskuler ini menjadi dasar anatomi untuk terjadinya manifestasi neuroiskemik pada CES. ${ }^{8-9}$ Akar saraf cauda equine mudah mengalami cedera akibat kompresi atau tarikan. Akar saraf cauda equine merupakan saraf otonom dan tidak memiliki selubung sel Schwann. ${ }^{9}$

Kelemahan tungkai, hipoestesi pada daerah pantat dan kemaluan, disfungsi ereksi mengarah pada penekanan pada akar saraf cauda equine. ${ }^{10}$ Stenosis pada thoracal 1112 ini dapat menyebabkan timbul cauda equine syndrome. Keluarnya saraf cauda equine pertama dapat melalui level thoracal 10, sehingga adanya stenosis pada level tersebut ke bawah dapat menimbulkan gejala cauda equine syndrome. ${ }^{11-13}$

Pemeriksaan penunjang MRI meyakinkan bahwa adanya spinal stenosis berat pada level vertebra thorakal bawah, sesuai dengan gangguan neurologis hipoestesi setinggi level tersebut. ${ }^{14}$ Sekitar $52-85 \%$ stenosis thoracalis terjadi pada daerah lower thoracal seperti thoracal 1012. ${ }^{15}$

Pada studinya, Fushimi et al menuliskan kasus canal stenosis thoracal yang tandem dengan canal stenosis lumbal dengan dilakukan operasi pada level lumbal menunjukkan adanya perburukan. ${ }^{7} \mathrm{Xu}$ et al, pada tulisannya menjelaskan tentang adanya occult thoracic spinal stenosis yang bisa terlewatkan pada kasus patologis lumbal seperti spondilitis TB lumbal. ${ }^{15}$ Dengan MRI sampai dengan thorakal ditemukan adanya stenosis setinggi thorakal bawah. ${ }^{15}$

Pada kasus kami, dilakukan operasi dekompresi selektif dengan laminotomy pada level thoracal sesuai dengan segmen gambaran klinis dan radiologis sesuai derajat penekanannya. Hasilnya cukup baik dilihat dari perbaikan gejala klinis dan penilaian nyeri pascaoperasi terutama untuk pasien kedua, dimana operasi dilakukan 2 minggu pasca keluhan cauda equine. Sedangkan pasien pertama dengan keluhan cauda equine yang sudah 1 tahun sulit membaik. Tindakan operatif pada kasus cauda equine syndrome harus segera dilakukan, pada kasus yang masih baru perbaikan klinis sangat signifikan dibandingkan dengan kasus yang sudah lama. ${ }^{16}$

\section{KESIMPULAN DAN SARAN}

Pada kasus pasien dengan keluhan cauda equina syndrome, spinal stenosis 
thoracalis bisa merupakan penyebabnya, meskipun jarang ditemukan. Penyebabnya adalah penekanan pada daerah thorakal bawah yang merupakan awal keluarnya akar saraf cauda equina. Untuk menghindari misdiagnostik stenosis thorakal, sebaiknya dilakukan pemeriksaan MRI thorakal pada kasus cauda equine syndrome, selain MRI lumbal. Tindakan operatif harus segera dilakukan ketika muncul gejala cauda equine syndrome karena mempengaruhi prognosisnya.

\section{REFERENSI}

1. Herkowitz, H. et al. Rothman-Simone: The Spine. Sixth Edition. Philadelphia. Saunder Elsevier. 2015:1064-1074.

2. Chen Z dan Sun. Clinical Guideline for Treatment of Symptomatic Thoracic Spinal Stenosis. Orthopaedic Surgery 2015;7:208-212.

3. Young, F dan Baron E. Acute neurologic deterioration after surgical treatment for thoracic spinal stenosis. Journal of Clinical Neuroscience. 2001; 8(2): 129132.

4. Toribatake Y, Baba H, Kawahara N, et al. The epiconus syndrome presenting with radicular-type neurological features. Spinal Cord 1997;35:163-170.

5. Solomon, Luis; Warwick, D dan Nayagam, S. Apley's System of Orthopaedic and Fracture. Ninth edition. London: Hodder Arnold. 2010:254.

6. Thompson, John C. 2010. Netter's Concise Orthopaedic Anatomy. Second edition. Philadelphia: Saunders Elseviers: 60.

7. Fushimi $M$. et al. Neurological deterioration due to missed thoracic spinal stenosis after decompressive lumbar surgery. Bone Joint J 2013;95B:1388-91

8. Parke WW, Gammell K, Rothman RH: Arterial vascularization of the cauda equina. J Bone Joint Surg Am 1981; 63:53-62.

9. Dhokia R, Eames N. Cauda Equina Syndrome: A review of the current position. Hard Tissue 2014; 18(3):7.

10. Korse NS, Jacobs WCH, Elzevier HW, Vleggeert Lankamp CLAM: Complaints of micturition, defacation and sexual function in cauda equina syndrome due to lumbar disk herniation: a systematic review. Eur Spine J 2013; 22:1019-1029.

11. Rydevik BL, Myers RR, Powell HC: Pressure increase in the dorsal root ganglia following mechanical compression: Closed compartment syndrome in nerve roots. Spine 1989;14: 574-576

12. Gardner A, Gardner E, Morley T. Cauda equina syndrome: a review of the current clinical and medico-legal position. European Spine Journal 2011;20(5):690--697.

13. Cramer DG and Darby SA. 2014. Anatomy of the Spine, Spinal Cord, and ANS. 3rd Edition. Philadelphia. Elsevier: 6-7.

14. Millar L, Robinson A, O'Flaherty M, Eames N, Johnston N, Heyburn G. Magnetic Resonance Imaging in a Patient with a Dual Chamber Pacemaker. Case reports in medicine. 2011;2010.

15. $\mathrm{Xu}$ et al. Occult Thoracic Spinal Stenosis: A Case Report and Literature Review. J Spine 2015; 4: 236.

16. Park BC, Min WK, Oh CW, Jeon IH, Kim SY, et al. Surgical outcome of thoracic myelopathy secondary to ossification of ligamentum flavum. Joint, bone, spine: revue du rhumatisme. 2007; 74: 600-606. 